BARTOSZ LUTOSTAŃSKI

University of Warsaw*

iD https://orcid.org/0000-0001-6345-3275

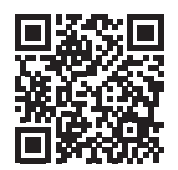

\title{
Across the Boundaries of Signs and Media: On Transgeneric Qualities of Selected Contemporary Fiction
}

\begin{abstract}
The following article construes the novel as a genre and explores how the innovations of utilizing multiple semiotic resources and media platforms are transforming it these days. With Marisha Pessl's Night Film (2013) as the primary example I look into the properties of the multimodal and multimedia novel with a view to presenting various ways of transgressing the parameters of the traditional (monomodal and mono-medial) novel.

Drawing from L. Elleström's theory of "modalities of media” I seek to go to the depth of the semiotic and semantic mechanisms of Night Film and argue how the integration of the verbal and the visual renders a new reading experience. Also, on the basis of J.P. Bolter and R. Grusin's idea of hypermedia I claim that the multiplication of sign systems and media aims at enhancing the ontological illusion.
\end{abstract}


* Institute of English Studies, University of Warsaw ul. Hoża 69, 00-681 Warszawa

e-mail: b.lutostanski@uw.edu.pl

The following article has been proofread by the native speaker of English, Trevor Hill, lecturer of English at the University of Warmia and Mazury in Olsztyn. 
In his seminal work, Kinds of Literature. An Introduction to the Theory of Genres and Modes (1982/1997), Alastair Fowler proposes to consider literature as an "aggregate" genre (2-6). The novel, too, can be deemed as such by extension, construed as an abstract and conventional entity, and specific form of interpersonal and intersubjective communication. In the following paper, I discuss selected techniques and strategies that modify the novel's longstanding genre conventions and affect the commonly accepted communication patterns due to a widespread use of nonverbal semiotic modes and multiple media. The transformations, chiefly technological, which in turn can potentially become semiotically significant as well, force us to conceptualize the novel's generic status differently by looking into its newly acquired properties.

In the following sections I first tackle the denotation of three key concepts: mode, medium and genre. My special attention is on the first term inasmuch as it forms the basis of the theory of the so-called multimodality, an exceptionally fashionable phenomenon across the humanities nowadays. However, I critique it by pointing out some examples of inconsistency and incoherence of its practitioners, and offer a more adequate term, multisemioticity.

Subsequently, I explore the multisemiotic and multimedia strategies in Marisha Pessl's Night Film and argue that its principle function is that of realism, or, in lieu of two media scholars, hypermedia realism. I do so because the novel's accumulation of a multitude of semiotic and media resources aims to represent an authentic and non-mediated view of a reality. The representation in this novel, however, cannot be authentic and non-mediated but rather hypermediated and simulated in a Baudrillardian sense.

The following paper, admittedly, constitutes an introduction, a prolegomenon, to the more in-depth, extensive and nuanced exploration into the contemporary novel which I intend to embark on in the foreseeable future. For the time being, I focus on Marisha Pessl's thriller/crime novel and look into its multisemiotic and multimedia apparatus. Before doing so, I want now to map out the theoretical background determined by the three vital concepts.

\section{Genre, Medium and Mode at Conceptual Crossroads}

Since the turn of the century, especially after the publication of Mark Z. Danielewski's House of Leaves in 2000, there has been an explosion of new types of novel. One of them seeks to combine the traditionally dominant verbal substance with other semiotic modes, mainly 
visual. Consequently, it undermines the traditional superiority lent to the verbal substance of the novel; in works of heterogenous material the word content constitutes only one semiotic dimension out of many. Also, such a novel questions the dominance of the format of the book as the main technological support of the novel in general. In recent years other important phenomena within the novel genre have occurred as well. They have, so far, met with scant critical attention despite the fact that they are vital for the ontology of the novel. What I have in mind has to do with the integration of not only various semiotic modes but also various media within a given work.

Mode, medium and genre are admittedly complex phenomena. Being the oldest, I shall tackle the third one first. "Genre" and "genre studies" go back to antiquity and have formed a basis for understanding and thinking about literary works for millennia; they have also played a vital role in the history of literature. Having survived ferocious attacks from postmodernist writers and theorists, such as Raymond Federman and Jonathan Culler ${ }^{1}$, genre has regained its important position in both literary studies and in the humanities. The fact that genre studies no longer tackle literature exclusively is one of the most important features of the discipline in this day and age. That is to say, literary genre studies are in no way dominant or privileged anymore; media studies, film studies, philosophy, law, and arts have all contributed to how we think about and perceive the concept of genre. What is also important, the revolutionary days of the 1980s and 1990s left genre studies equipped with a new understanding of its own fundament: genre ${ }^{2}$.

Genre is a tripartite entity: it is abstract, conventional and communication-oriented. Briefly speaking, the abstractness of the genre refers to it being a theoretical construction, a paradigm or prototypical "combination of devices" which serves as a matrix for all (literary or otherwise) productions. Crucially, its point of departure is a group of actual artistic and/ or social practices and the point of arrival is the constructing of definitions of genres with relevant systems and taxonomies. Effectively, the genres are a historical phenomenon, open to modifications and novelties but also prone to being out of favor or dead.

Secondly, conventionality implies that the genre is a set of conventions, that is, reproducible formal, stylistic and/or thematic features. As Michał Głowiński claims in his important article on a historical dimension of genres, the genre consists of invariants, a genre's conventions that persist over time and facilitate its existence, and variants, those conventions that are new and warrant its change and development (2007: 85). Thus, the genre's conventionality is a game of identity and difference and can be considered gradable since a given work is more or less conventional depending on the degree of original and non-original features.

Finally, the genre is a form of communication. A repertoire of established artistic conventions and paradigms, it constitutes a common ground for both the addresser and the addressee; their shared familiarity with and consciousness of a genre enables them to communicate properly and effectively. Glowiński argues that this facet of the genre has a social significance as both communication participants ought to adhere to a group of factors and means facilitating a type of literary communication and understanding; the genre is not only a model of

1 See Surfiction. Fiction Now... and Tomorrow (1975), ed. Federman and with a contribution from Culler.

2 What follows is a gist on genre studies in Poland from two volumes: Polska genologia literacka [Literary Genre Studies in Poland] (2007) and Polska genologia [Genre Studies in Poland] (2009). I also lay it out in my most recent publication (in Polish), Prolegomena do genologii transmedialnej [A Prolegomenon to Transmedia and Genres]. 
creating but also of receiving a text (78-83). The consequence of this is normativity (a necessity to conforming to and emulating a generic pattern) and axiology (a basis for evaluating a given production as a successful realization of the pattern $)^{3}$.

The novel can be construed as a genre because it consists in abstract and conventional properties and aims at interpersonal communication. Narrator, plot, characters, flashbacks, or rising action are all familiar to any reader of the novel, others might even recognize diegesis and hermeneutic code. These components have a practical effect; seeing "A Novel" on a cover determines the way we read and comprehend what is inside. And, arguably, what is inside Marisha Pessl's Night Film, my object of analysis in this paper, transcends, or even violates, the parameters of the genre of the novel, although some might asseverate that it is a specimen of a "genre fiction". However, the novel in question employs non-verbal semiotic resources and spreads its tentacles across multiple media platforms what, theoretically (generically), should not happen.

The first way of transcending the novel's parameters I want to focus on is an extension of its content across various media. Medium is an intermediary, something that works in the middle, a channel between the addresser and the addressee in the process of communication (Elleström 2010: 12). Marie-Laure Ryan, one of the most important advocates of "mediaconsciousness" across the humanities of late, maintains that a medium is of three dimensions: technical, cultural and semiotic (2014: 16-25). As a result, the medium has three fundamental manifestations: a medium can be a transmitter (for example, film, music and book as distinct media), a form of communication (literature, TV, press or game), or a sign (image, sound and language). The last dimension being in a detrimental proximity to modality (see the discussion below), it seems most reasonable to follow Henry Jenkins's understanding of a medium as "technology enabling communication" and "a set of associated 'protocols' or social and cultural practices that have grown up around that technology" (2006: 13-14).

As for the mode, another area of the potential transgressions of the traditional novel parameters, the pioneers of studying multisemiotic phenomena, Gunther Kress and Theo van Leeuwen, define it as "semiotic resources" that "allow the simultaneous realisation of discourses and types of (inter)action" (2001:21). Ruth Page explains the mode as "a system of choices used to communicate meaning" (2010: 6). The term has made an unbelievable career of late and has become a household name in the humanities, especially when denoting the employment of multiple semiotic resources, then it goes by the name multimodality ${ }^{4}$.

As Kress and van Leeuwen observe, "For some time now, there has been, in Western culture, a distinct preference for monomodality" (2001: 1). Researchers generally tend to abstain from sustained explorations into a variety of semiotic resources utilized in a given work but rather focus on a selected one and examine it in isolation. Ruth Page negatively characterizes such research tactics as "mode-blindness". She lays the blame for it on Structuralism, whose "significant legacies" are "the assumption of monomodality and the privileging of verbal resources" (2010:3). Within the theory of the novel, too, "the preference for monomodality" has been common and widespread. On the one hand, Alison Gibbons asserts that

3 Another, and significantly more extreme, take on this component of the genre's characteristics is that of Jason Mittell. See his Genre and Television, pp. x-xii and Chapter 2.

4 See for example: Multimodal Studies. Exploring Issues and Domains, eds. K. O'Halloran, B.A. Smith, The Routledge Handbook of Multimodal Analysis, ed. C. Jewitt, and two volumes of Media Multimodalne, eds. I. Hoffman, D. Kępa-Figura. 
literary criticism has persistently "favoured the word" (2011:1) and, on the other, according to Wolfgang Hallet, the "traditional novel is basically monomodal" (2014: 152; italics in original). In other words, it is universally acknowledged that written language constitutes the fundamental semiotic mode for the novel and that theory has upheld this idea despite historical evidence. When you study disparate research on the novel, there is no mention or discussion of nonverbal substance, and Laurence Sterne's Life and Opinions of Tristram Shandy, Gentleman (1759-1767) is an odd exception. It is as if the material substance of the novel, words printed on a white page in a paper-bound book, has been automatically erased from perception when read. A good case in point is typography, an insurmountable proof of the novel's visual dimension, which instead serves as "an aspect of literary narratives that readers tend not to notice much, especially not when the narrative is set in conventional typefaces such as black Times or Palatino" (Nørgaard 2010: 116).

Numerous contemporary novels can integrate a number of different semiotics modes, chiefly the verbal with the visual. The result is the multimodal novel, which is characterized, using Gibbons' words, by a constant interaction of "different modes of expression" in the "production of narrative meaning" (2011:2). A crucial stipulation at this juncture is that the distinct modes need be placed within one work, not autonomously of or separately from it, and that they are all examined "with equal priority" with other modes (Page 2010: 4).

However, Kress and van Leeuwen's theory of multimodality has been repeatedly criticized. Marie-Laure Ryan argues that their attempts to "list and classify modes of signification are similar in their apparent randomness to Borges's Chinese taxonomy" (2001: 28). In addition, far too often have the researchers into this phenomenon been confusing and careless in making the fundamental distinctions. In her introductory essay to New Perspectives on Narrative and Multimodality, Ruth Page herself commits a mistake of using the key concepts, "modes" and "modalities", to address two completely different contexts: semiotic resources, in line with the theory of multimodality, as well as human senses. As a result, the figure which neatly presents "Dimensions of the Multimodal Ensemble" and comprises "textual resources", such as words and images, "platform of delivery", digital screen and printed page, "physical environment", private or public, for instance, and "sensory modalities", sight or hearing (2010: 8), leads to the opacity as to what modes and modalities really are: are they signs or sense systems, or both?

In another contribution to New Perspectives on Narrative and Multimodality, Nina Nørgaard in footnote 5 quotes yet another meaning of modality as "various semiotic resources for expressing 'as how true' or 'as how real' something is represented" (2010: 125). The author draws the definition from linguistics (from M.A.K. Halliday, to be exact) and thus goes against the majority of the papers in the volume which derive their understanding of the phenomenon in question from Kress and van Leeuwen. As a result, when discussing modality of the text's typography she is in fact looking into "probability, usuality, obligation, and inclination" rather than semiotic resources (2010: 118).

In order to avoid further misunderstanding and opacity I would like to abandon the term "multimodality" and in its stead utilize "multisemiotic" as denoting "multiple semiotic resources". In addition, I adapt the meaning of "mode" from Lars Elleström, whose salient work on semiotics has gone unnoticed by Page, Gibbons, Hallet and other researchers into multimodal fiction. In his article "Modalities of Media: A Model for Understanding Intermedial 
Relations", Elleström defines "mode" as "a way to be or to do things" (2010:12) and therefore the "modality" pertains to the manifestations of various meaning-making phenomena. The semiotician enumerates four modalities: material, sensorial, spatiotemporal, and semiotic.

The first modality, examples being film's flat surface of changing images with sound waves and theatre's three-dimensional stages peopled with human bodies and physical objects, is "the latent corporeal interface" (2010: 17). The second one is "the physical and mental acts of perceiving the present interface of the medium through the sense faculties" (2010:17). In other words, Elleström stipulates here which senses are employed when perceiving an object or event. Reading a novel requires the employment of at least our eyesight whilst watching a TV show that of eyesight and hearing. The spatiotemporal modality "covers the structuring of the sensorial perception of sense-data of the material interface into experiences and conceptions of space and time" (2010: 18). The perceivers map the perceptions along four dimensions (width, height, depth and time); to give an example, a photograph is static inasmuch as it lacks temporal progression as opposed to a dance performance which fundamentally hinges upon change in time.

The final modality, the semiotic one, is about meaning. "Since the world is meaningless in itself, meaning must be understood as the product of a perceiving and conceiving subject situated in social circumstances," concedes Elleström (2010: 21). This modality constitutes a fourth stage in a meaning-making process, beginning with the material interface and moving to perception via specific senses to attributing spatiotemporal features before a meaning is made. "The semiotic modality thus involves the creation of meaning in the spatiotemporally conceived medium by way of different sorts of thinking and sign interpretation" (2010:22).

As a literary genre the novel can be conceptualized through Elleström's modalities. The traditional novel is a three-dimensional object whose content is derived from a two-dimensional (printed paper) surface. It is exclusively language-based; its semiotic modality is therefore symbolic. Materially it is static although its narrative is inevitably a temporal concept, called "virtual time" (Elleström 2010: 20). Moreover, we perceive it through one sense system - eyesight. What happens, however, when most or all of these parameters (modalities) are transgressed or profoundly modified in one novel or another? Do we still deal with a novel? If not, what then? If so, what kind of novel is it? I will now consider some of the implications for the novel as a result of an unorthodox treatment of its genre characteristics. An example of the multisemiotic and multimedia novel is Marisha Pessl's Night Film.

\section{Words, Images, and Other Dangerous Things}

Marisha Pessl's Night Film was a success story after its publication in 2013, present in The New York Times' 2013 bestseller list and nominated for the 2013 Shirley Jackson Award. It is a mystery/thriller novel in which Scott McGrath, an investigative journalist in desperate need of professional and private rehabilitation, teams up with a drug dealer and a wannabe actress to resolve the enigmatic death of one Ashley Cordova, daughter of a secretive, reclusive and cult-followed director, Stanislas Cordova. The plot being typical for the thriller genre and its resolution rather disappointing and deflated, Night Film's main appeal lies in its form (and format). Within the novel there is a myriad of materials, such as newspaper and magazine articles, cuttings, documents, reports, maps, emails, hand-written notes, and photographs. All these resources can be located along the spectrum from the textual to the visual, with an admixture of both in the middle. 
At one end there is the text of the novel itself - a "pure" textuality in the sense of being composed solely of word substance ${ }^{5}$ - and at the other - a "pure" visuality: a photograph of Ashley Cordova on page 148, the cover of Ashley's record that McGrath listens to (37), a faded and blurry photo of Ashley and Hopper (351), or the three black pages (421, 422 and 482). The middle ground is occupied by an array of textual-visual materials.

Starting from the text end of the semiotic continuum, there is a group of short texts in various fonts: search history from Beckman's Firefox (50), an "Enchantments" shop with witchcraft goods (228) and a sign inside about not selling "black magick supplies" (229), an entry from a book on witchcraft read by McGrath in the shop (240), Hopper's text message (332), and, finally, a wooden information sign from one of Cordova's films (448). Further, there are two emails: one from the Briarwood Hall Hospital's Elizabeth J. Poole to Scott McGrath informing him about the possibility of visiting the facility (88) and from McGrath's attorney, Stuart Laughton, who forwards a message from Olivia E. du Pont's PA (291); both are designed to resemble an email box interface and its indispensable elements: "from", "subject", "to" and "date" lines at the top, the content of the message, and the usual tools such as "Delete", "Not Junk", "Reply", "Reply All", "Forward", and "Print". As well as the emails, there are messages from Hopper's phone in the shape of speech bubbles (resembling those being used in text messaging via smartphones) (68-69).

Other text-dominated materials comprise diverse documents: a typed transcript of phone conversation between McGrath and an anonymous caller (31-33) and the dossier from his first investigation into Cordova from 2006 (151-159) consisting of old-fashioned font texts, photographs stapled to pages, hand-written annotations, and a map of Crowthorpe Falls and the Peak; there are also the police's documents, the Briarwood Hall admission form and the police report of Ashley's suicide (45-48), McGrath obtains from his informer as well as a printout of a page from the National Center for Missing \& Exploited Children (519) with hand-written notes on it.

Throughout the novel we also come across images presenting a reproduced Sneak magazine interview with Peg Martin (267-268), one of the few available actresses who played for Cordova, an excerpt from the Newsletter of Amherst College from autumn 2005 about Ashley Cordova (36), containing a photo of her at the piano, and the famous, unfinished Rolling Stone interview with Stanislas Cordova, hedged with two black pages at the beginning and the end (588-593).

The two interviews, from The Sneak and the Rolling Stone, bear similarity to the four online articles presented on the novel's pages in the form of screenshots. These are: The New York Times online article about Ashley Cordova's recent suicide (3-4), Time magazine's online article about her father, Stanislas (5-22), the Vanity Fair online profile of Ashley seen from the perspective of her Amherst College roommate, Emma Banks (223-227), and an online article about kirin (289). There are also screenshots of McGrath's visit to a secret website about Cordova, the Blackboards (89-90 and 165-185).

In the material whose dominating semiotic apparatus is the visual substance are the cuttings. They originate from various sources but mainly they are photographs of sheets of paper, complete or in part. These include: a clipping from a directory book with the telephone number and address of Morgan Devold (114), a handwritten message from Ashley to Morgan

5 For the reasons of clarity, I neglect the issue of the "visuality" of text in the form of various fonts, their size, overall typography on page etc. 
(with an appeal for help) (126), Albany's Times Union newspaper report about the alleged suicide of Genevra Castagnello (163), a Klavierhaus guestbook with Ashley's handwritten note of current dwelling (202), and a report of Orlando Wang's death (352).

All of these resources occupying the middle range between the text and the image in Night Film should be classified as predominantly visual for two main reasons. Firstly, the short inscriptions in different fonts, the text-dominated screenshots from websites or photographs of paper magazines stand well apart from the main text of the novel, and routinely combine different-font texts, bolding, typical newspaper typography, and graphics. Secondly, the materials are non-textual in that they are crude materials crude materials, unfiltered through the protagonist-focalizor and unmediated in the narrative. As a result, Night Film is a multisemiotic novel whose semantic mechanism draws from two major semiotic systems: the word and the image. At times, complex entities are constructed - those which combine both components (an image of a text) or one component with another one (an image of an image). The novel also aims to incorporate other media (mainly online and printed journalistic articles) by reproducing their format, form and content "verbatim".

To sum up my heretofore analysis of the novel, Marisha Pessl's Night Film is a multisemiotic work whose material modality is that of a printed book, and the verbal and visual substances located on the flat surface of pages. As such it has a solid, two-dimensional material interface. The material is to be perceived by means of sight, albeit in two different ways: when reading the text of the novel and when looking at a photograph. When it comes to the spatiotemporal modality, the novel is essentially spatial with the caveat that its narrative is time-driven in the sense of the plot development and sequentiality. Finally, the semiotic modality of the thriller, dominated by word and image, is symbolic and iconic respectively. That is to say, word has the symbolic sign functions, whereas image is of the iconic sign function. As a result, the signification process in Pessl's novel is in actuality bipartite.

However, some of the visual components employed in Night Film are not simply iconic in that they resemble other entities, such as a hand-written text, report, map, or a photograph of a woman. The screenshots of The New York Times or the Time magazine articles reproduce the inherent properties of online press material: typography and essentially multisemiotic character. A case in point is a report of Ashley Cordova's tragic death from The New York Times. The novel's pages three and four feature a screenshot of an allegedly authentic article from the famous newspaper, "Ashley Cordova, 24, Found Dead". The layout of the page strikingly resembles that of the NYT; it also includes a photograph of Ashley and several comments below the piece. Unfortunately, neither the NYT or Time hyperlinks function ("Page Not Found"), which proves that the screenshots are not authentic but are simply made to look like ones. The same must be said about the Blackboards, a secret website of the Cordovites, Stanislas Cordova's most avid and faithful fans, unavailable for any random Internet user, featuring an array of information about the director, his life and films, schedules of secret "red-band" screenings of Cordova's films, and so on.

The medium of press is therefore iconically represented in the medium of the novel along with its features. Importantly, the material modalities are strikingly different: one is of the printed novel and the other one is of the online newspaper/magazine. In addition, the former seeks to copy the inherent features of the latter with different results; the NYT article about Ashley Cordova's death in the novel cannot be scrolled down and therefore spills over onto the following page whereas the Time piece reproduces the fragmented content by presenting 
each item of information on a separate piece of paper of the novel, yet instead of clicking through, the reader simply turns the pages. This is also the case of other online resources presented in the text: the medium of the novel tries in vain to mimic the medium of the online press. By failing so, the old medium (novel) manifests its limitations in the face of the new medium (the Internet).

In order to comprehend one medium's reproduction of another one I might borrow the key term from Jay David Bolter and Richard Grusin's important study, Remediation. Understanding New Media (2000). However, there is a major difference between what Bolter and Grusin discuss and what I have just concluded. The authors define remediation as digital media representing or reproducing properties of old media (45). In Night Film it is the other way round; the novel seeks to imitate the online press and, as I contended, it cannot successfully do so without, for instance, the awkwardness of page-turning (instead of a slick scrolling down) and inadequacy of this closed-ended medium (instead of the online webpage allowing for users' continuous interaction in the comments section). However, my understanding is that the novel incorporates the visual resources and remediates online press with a view to enhancing ontological illusion. To draw from Bolter and Grusin again, I can say that Night Film is a case of hypermedia.

Bolter and Grusin point out the historical oscillation between immediacy and hypermediacy (2000: 4-5). "This oscillation is the key to understanding how a medium refashions its predecessors and other contemporary media. Although each medium promises to reform its predecessors by offering a more immediate or authentic experience, the promise of reform inevitably leads us to become aware of the new medium as a medium. Thus, immediacy leads to hypermediacy" (19). The latter "multiplies the signs of mediation and in this way tries to reproduce the rich sensorium of human experience", it "acknowledges multiple acts of representation and makes them visible" opening on to "other representations or other media" (33). Therefore, hypermedia Night Film seems to be seeking "the real by multiplying mediation so as to create a feeling of fullness, a satiety of experience, which can be taken as reality" (2000: 53).

In addition, the hypermedia goes hand in hand with the traditional status of language in fiction. As I observed above, the medium of the novel typically strives to erase its materiality so as to achieve autonomy as "a window on" (Bolter and Grusin 2000: 33) or "an undistorted mirror of" the real world (Palmer 2008: 491) in an identical fashion as painting. Bolter and Grusin argue that painters used to "erase" the surface of the picture plane in order to "conceal and deny" that the process of painting ever occurred (2000: 25). Night Film utilizes two available strategies to erase all traces of mediation and pass itself off as more realistic: language, which readers routinely overlook as a signification system, and hypermedia. By doing so, the novel becomes symptomatic of contemporary culture which, to quote from Bolter and Grusin again, "wants both to multiply its media and to erase all traces of mediation: ideally, it wants to erase its media in the very act of multiplying them" (2000: 5) because language "bravely denies the fact of mediation" whereas hypermedia strives for complete rendition of reality (2000: 53).

To recapitulate, Marisha Pessl's Night Film is a multisemiotic novel, a static, two-dimensional object accessed exclusively through eyes, with the bipartite semiotic modality: symbolic language and iconic image. One of the most unusual properties of the novel is its embeddedness of symbolic and iconic signs: the photographs (screenshots) of online press 
materials (composites of word and image) pertain to a complex structure of the iconicity of symbolic and iconic resources. What is more, remediation serves as an iconic rendering of an autonomous medium in the novel medium with the results of hypermedia (icon within icon and medium within medium). However, there is more to Night Film than that because Pessl's work is accompanied by the so-called Night Film decoder.

The decoder offers "bonus content" available from Marisha Pessl's website or a special application for Android and iPhone smartphones. The content the characters are familiar with but rarely, if ever, mention is presented in a direct, unfiltered and non-mediated way. Free from the shackles of the medium of the novel, it acquires an independent status. This is the case because the materials display a loose and optional connection with and reference to the novel. In actuality, few readers are familiar with the decoder in the first place $^{6}$ and secondly the documents do not influence the plot in any significant way.

The content provided by the decoder includes: posters of all of Cordova's movies; a trailer of the Lovechild, a film by Cordova; a semester syllabus on the course about Cordova's films taught by film critic, teacher and Cordova fan Wolfgang Beckman's semester syllabus on the course about Cordova's films; an audio recording of a court statement made by a killer who murdered his victim in a way copycatted from one of Cordova's films; a recording from a CD Ashley Cordova made as a teenager; an audio report from the Briarwood Hall about the new patient, Ashley; an audio of Inez Gallo's acceptance speech at the 1979 Oscars gala when Cordova's film, Thumbscrew, won the best picture award; an incomplete audiobook of a children's book; a reading of T.S. Eliot's Prufrock; or even “The Personal Diary of Miss Lulu Swallow", the female lead from the Thumbscrew, in a PDF format.

Looking into their semiotic status, the "Diary" and Beckman's syllabus are primarily textual whereas the remaining materials are predominantly visual, auditory or both. The first group consists in the posters; the second in the doctor's report, the audiobook, the acceptance speech, the interview with the murderer, the reading of Prufrock, and Ashley's music. Finally, there is the Lovechild trailer that combines images with sounds. The audio and audiovisual content accessible via the Internet effectively renders the Night Film not only multisemiotic but also multimedia.

The multisemiotic character of the Decoder is straightforward. By granting access to other visual as well as auditory content, Night Film makes use of a rich repertoire of semiotic resources - words, images and sounds - received from a printed page, digital screen and sound waves, and processed by eyesight and hearing (at times simultaneously). Having to use both the book and an electronic device (a computer or a smartphone) makes the physical experience doubly complex due to two disparate interfaces, albeit both are flat and twodimensional. Initially, the Decoder application was supposed to be used in such a way that when reading the novel, the reader would scan images of a bird scattered across the novel and access the extra digital materials on their phone or tablet. Thus, there would be frequent transitions in using the book and the app. Finally, in terms of the semiotic modality, to the

6 Only a handful of reviewers from Amazon mention the decoder and some of those admit to not engaging in it (John Hovig, five-star rating, wrote: "P.S. I didn't engage in the multimedia. The modeled images and faux news pages in the book were brilliant. I really loved those. But I didn't go to youtube or click on anything in the book. I don't feel I missed anything. I'm not going to take anything away from those who enjoyed those elements. I'm just saying I don't think I needed them, simply to reassure anyone who might be suspicious of a book which uses them."). 
symbols of language and the icons of images I need to add the complex semiotic potential of a variety of sounds available in the decoder, including the human voice, piano music, or the sound of clapping. Clearly, Night Film is a multisemiotic and multimedia novel.

\section{Conclusions}

In the concluding sections of my paper I would like to tackle two issues: the motivation of utilizing the multiple semiotic resources and media platforms as well as the effect they exert on the novel as a genre.

Firstly, all the materials, irrespective of their in-book or out-of-book origin, have two major functions: offering a direct and unfiltered access to the "raw" resources at the investigators' disposal and thus boosting the realist effect. The screenshots from Time and Vulture, or photographs of authentic geographic locations in South America all aim to heighten the readers' impression of the story spilling over the fictional brims into the factual domain. Likewise, Ashley's medical history accounts which McGrath receives from a policewoman and the notes and photographs from his previous investigation into Cordova imitate, respectively, hospital documents, a police coroner's report, and typed statements accompanied by handwritten annotations and photographs clipped to the sheets of paper. Consequently, the reader is invited or compelled to fact-check any piece of information passing off as "real", for instance, to verify the existence of Stanislas Cordova as a mysterious director they have simply never heard of. The readers are apparently expected to doubt and question the borderline between truth and fiction; just like the protagonist, Scott McGrath, does at one of the turning points of the story as he is led to believe that his sleuthing activities are closely controlled by Cordova and he himself comes to play a role in a stratagem carefully and consummately engineered by the infamous director with a view to, at best, derailing his investigation or, at worst, driving him mad.

The above realist issues are intricately related with the formal ones. The webpages and articles, reports and hand-written notes, photographs, a film trailer and posters, an audio recording of a crime investigation, or a reading from Eliot's "Prufrock" may be said to constitute a pre-textual substance of the novel. The materials are not fully integrated within the novel by means of, say, heterodiegetic narration or internal focalization, and are not mediated by the narrator's discourse or the characters' minds; instead they are independent, unprocessed and raw, seemingly awaiting an incorporation into the "mature" text of the novel at some later stage or, by contrast, provided to grant the readers access to the crude evidence at the disposal of McGrath and his team, devoid of the filter of their subjectivity. Therefore, the materials pose as objective and authentic.

Finally, the multiplication of semiotic resources and media is to enhance realism by the sheer fact of the accumulation of signs, sign systems and media. In line with the media logic proposed by Bolter and Grusin, Night Film erases the traces of mediation via verbal material dominating in the novel as well as via a myriad of images and sounds within and without the book to produce an authentic, media-complex view of reality, not unlike the one we consume every day in the extratextual reality. The phenomena of remediation and hypermedia, however, leave no doubt as to the futility of this project in the novel as both single-semiotic as well as multisemiotic and multimedia practices inevitably expose the processes of mediation. In terms of Pessl's novel, the hypermedia in conjunction with diverse realism strategies leads to the construction of hyperrealism in which the more the signs give the impression of 
corresponding to the extra-textual reality, the more obvious the impression becomes. Night Film cannot be considered as a representation of reality but its simulation. The idea, borrowed from Jean Baudrillard, refers to the signs disguising the fact that they do not represent any reality but simulate one. "The excess of media," argue Bolter and Grusin, "becomes an authentic experience, not in the sense that it corresponds to an external reality, but rather precisely because it is does not feel compelled to refer to anything beyond itself" (53-54). A very good case in point is that when we enter the hyperlink from The New York Times or the Time magazine found in the novel, we end up nowhere; "Page Not Found".

There is one vital implication for the readers, or I shall say receivers, of the novel. Additional competences on the reader's part to decode Night Film are prerequisite. Multisemiotic and multimedia, the novel is necessarily policodified in the sense that each system requires one code and appropriate decodification strategies. This point is highlighted by Wolfgang Hallet; he claims that a multisemiotic work necessitates a multiliterate reception: “... on the one hand, the reader must decode and comprehend each of the semiotic modes utilized and displayed in the novel in its own right. ... On the other hand, the reader must be able to understand the semiotic interplay of all these modes and often of visual modes and verbal discourse in particular ...” (2014: 168).

Eventually, when it comes to the genre matters it is apparent that Night Film in fact is a novel. The way it combines multiple semiotic and media resources, however, profoundly modifies and makes the genre an example of a new species - the multisemiotic and multimedia novel, and can serve as matrix for emergent literary productions. The material modalities of this type of novel are indicative of a multiplication of latent physical interfaces: two-dimensional and solid surfaces of a book, a smartphone, a tablet or computer screen. Next to the routine sense experiences through the eyes, the readers use their hearing and touch, or even their whole body when operating an electronic device and hovering it over the text of the novel. The various separate interfaces aim to create a coherent and unified storyworld in which materials from outside the book complement the novel's content. At the same time, symbols, icons and indices come to form the global semiotic modality and become recognizable as the reproducible formal and stylistic features of the multisemiotic and multimedia novel.

Apparently, this emergent genre, a consequence of nearly two-decade-long experimentation with modes and media in fiction with House of Leaves (2000) by Mark Z. Danielewski, $S$. (2013) by Doug Dorst and J.J. Abrams, PRY (2013) by Samantha Gorman and Danny Cannizzaro, or The Pickle Index (2015) by Eli Horowitz as selected examples, has finally managed to constitute a proper and effective artistic communication between both the authors and the readers. Marisha Pessl's Night Film was the first multisemiotic/multimedia novel to enter a bestsellers list, which leaves a lot of hope that, with the growing role of technology in our lives, the multisemiotic and multimedia novel will become even more common. 


\section{Bibliography}

Bolter Jay David, Richard Grusin (2000), Remediation. Understanding New Media, MIT Press, Cambridge MA.

Elleström Lars (2010), The Modalities of Media: A Model for Understanding Intermedial Relations [in:] Media Borders, Multimodality and Intermediality, ed. Elleström L., Palgrave Macmillan, Houndmills.

Fowler Alastair (1997), Kinds of Literature. An Introduction to the Theory of Genres and Modes, Clarendon Press, Oxford.

Gibbons Alison (2011), Mulitmodality, Cognition, and Experimental Literature, Routledge, London-New York.

Głowiński Michał (2007), Gatunek literacki i problemy poetyki historycznej [in:] Polska genologia literacka, eds. Cudak R., Ostaszewska D., PWN, Warsaw.

Hallet Wolfgang (2014), The Rise of the Multimodal Novel. Generic Change and Its Narratological Implications [in:] Storyworlds across Media, eds. Ryan M.-L., Thon J.-N., University of Nebraska Press.

Jenkins Henry (2006), Convergence Culture. Where Old and New Media Collide, New York UP, New York.

Kress Gunther, Theo van Leeuwen (2001), Multimodal Discourse. The Modes and Media of Contemporary Communication, Arnold, London.

Lutostański Bartosz (2019), Prolegomena do genologii transmedialnej, "Tekstualia”, vol. 58, no. 3.

Media Multimodalne (2018), eds. Hoffman I., Kępa-Figura D., Vol. I and II, Wydawnictwo UMCS, Lublin.

Mittell Jason (2004), Genre and Television. From Cop Shows to Cartoons in American Culture, Routledge, London-New York.

Multimodal Studies. Exploring Issues and Domains (2011), eds. O'Halloran K., Smith B.A., Routledge, London-New York.

Nørgaard Nina (2010), "Multimodality and the Literary Text: Making Sense of Safran Foer's Extremely Loud and Incredibly Close." New Perspectives on Narrative and Multimodality, ed. Page R., Routledge, London-New York.

Page Ruth (2010), Introduction [in:] New Perspectives on Narrative and Multimodality, ed. Page R., Routledge, London-New York.

Palmer Alan (2008), Realist Novel [in:] Routledge Encyclopedia of Narrative Theory, eds. Herman D., et al., Routledge.

Pessl Marisha (2013), Night Film, Random House, New York.

Polska genologia (2009), ed. Cudak R., PWN, Warsaw.

Polska genologia literacka (2007), eds. Cudak R., Ostaszewska D., PWN, Warsaw.

Ryan Marie-Laure (2014), Story/Worlds/Media: Tuning the Instruments of a Media Conscious

Narratology [in:] Storyworlds across Media, eds. Ryan M.-L., Thon J.-N., University of Nebraska Press, Lincoln-London.

Surfiction. Fiction Now... And Tomorrow (1975), ed. Federman R., Swallow Press, Chicago.

The Routledge Handbook of Multimodal Analysis (2016), ed. Jewitt C., Routledge, LondonNew York. 